\title{
High-Intensity Laser Therapy Can Be Beneficial in People With Subacromial Pain Syndrome, but We Need To Combine It With Exercise for Better Results: A Randomized Trial
}

Sevgi Sevi Yeşilyaprak ( $\nabla$ sevgi.subasi@deu.edu.tr)

Dokuz Eylül University

\section{Seda PASKAL}

Dokuz Eylül University

\section{Can KOŞAY \\ Dokuz Eylül University}

Onur HAPA

Dokuz Eylül University

Keywords:

Posted Date: May 5th, 2021

DOI: https://doi.org/10.21203/rs.3.rs-443029/v1

License: (c) (1) This work is licensed under a Creative Commons Attribution 4.0 International License. Read Full License 


\section{Abstract}

The authors have requested that this preprint be removed from Research Square. 